\title{
Could there be a fine-tuning role for brain-derived adipokines in the regulation of bodyweight and prevention of obesity?
}

\begin{abstract}
Russell E. Brown*
ABSTRACT: Obesity is one of the most prevalent medical conditions, often associated with several negative stereotypes. Although it is true that weight gain occurs when food intake exceeds energy expenditure, it is important to note that even a $1 \%$ mismatch between the two can lead to a substantial weight gain after only a few years. Further, the body appears to balance energy metabolism via an endogenous lipostatic loop in which adipose stores send hormonal signals (e.g. adipokines such as leptin) to the hypothalamus in order to reduce appetite and increase energy expenditure. However, the brain is also a novel site of expression of many of these adipokine genes. This led to the hypothesis that hypothalamic-derived adipokines might also be involved in bodyweight regulation by exerting some effect on the control of appetite or hypothalamic function. When RNA interference (RNAi) was used to specifically silence adipokine gene expression in various in vitro models, this led to increases in cell death, modification of the expression of key signaling genes (i.e. suppressor of cytokine signaling-3; SOCS-3), and modulation of the activation of cellular energy sensors (i.e. adenosine monophosphateactivated protein kinase; AMPK). Subsequently, when RNAi was used to inhibit the expression of brainderived leptin in adult rats this resulted in minor increases in weight gain in addition to modifying the expression of other adipokine genes (eg. resistin). In summary, although adipokines secreted by adipose tissue appear to the main regulator of lipostatic loop, this review shows that the fine tuning that is required to maintain a stable bodyweight by this system might be accomplished by hypothalamicderived adipokines. Perturbations in this central adipokine system could lead to alterations in normal hypothalamic function which leads to unintended weight gain.
\end{abstract}

\section{OBESITY AND INDUSTRIALIZED SOCIETIES}

Obesity has reached epidemic proportions making it one of the most common, costliest and deadliest health conditions in industrial societies. Several hypotheses have been put forth to account for the escalating body mass indices (BMI) including overeating and lack of physical activity. However, novel factors also appear to be contributing to this modern day epidemic, including inadequate sleep, increased environmental concentrations of industrial endocrine disrupters,

*To whom correspondence should be addressed:

R.E. Brown

1400 ave des Pins Ouest, Apt 401

Montreal, Qc

H3G 1B1

Telephone: 514-984-7877

Email: Russell.Brown@mail.mcgill.ca reductions in the number of smokers, to name a few (1). Although it remains clear that a positive energy imbalance exists, where food intake exceeds energy expenditure, it is worth noting that as little as a $1 \%$ imbalance can lead to a $1 \mathrm{Kg}$ weight gain within one year (2). $10 \mathrm{Kg}$ or more than 20 pound of weight gain over a single decade can be caused by mere 25 excessive calories per day. Thus even the most subtle mismatches in energy homeostasis can lead to significant changes in body weight over a relatively short period.

Within the last 15 years, the percentage of obese Canadians has more than doubled, and this trend does not appear to be subsiding (3). The proportion of overweight and obese children is also increasing at a staggering rate in North America (4). It has even been suggested that economically priced super sized car seats are now needed in the United States since nearly 300,000 children under the age of 6 exceed the current 
weight restrictions (5). For the first time in the last two centuries, population lifetime expectancy in the US is predicted to decrease by 0.33 to 0.75 years (6). This is due, in part, to the increased risk of developing diabetes, heart disease, cancer, and other co-morbidities that are associated with carrying excess body weight (6). Furthermore children are now being diagnosed with "adult" diseases such as non insulin-dependent diabetes mellitus (NIDDM). They are also at increased risk of developing cardiovascular diseases at much earlier ages. An estimated $10-20 \%$ of new pediatric diabetes patients in Canada are now due to type 2 diabetes (7). In addition to decreased life expectancy, it was estimated that obesity directly cost Canadians over \$4.3billion in 2001 (8), a figure likely to be much higher today.

Although diet and exercise are known to be highly effective at inducing weight loss, few individuals successfully maintain these reductions over the long term, suggesting that these interventions alone are an ineffective means to treat obesity (9). Although obesity prevention becomes an important strategy, major investments are needed to target the underlying physiological mechanisms that will favor weight loss and prevent the development of obesity. More importantly, there is a need to identify effective therapies that promote sustainable reductions in bodyweight. One approach is to investigate potential molecular mechanisms that could be used as pharmaceutical targets to reduce bodyweight, in addition to facilitating the maintenance of this weight loss.

There is a large body of evidence suggesting that obesity includes a substantial genetic component (1012). Early obesity studies lead to the hypothesis that humans developed thrifty genes that offered protection during times of famine and low availability of food sources (13). Combined with improvements in agriculture leading to an abundant and stable food supply, and reduced daily physical activity (14), thrifty genes have rendered us susceptible to gain and store the excessive weight. It has also become evident that not only do we need to consider what genes are present, but how they might be differently expressed due to imprinting and epigenetic modifications that can occur during fetal programming (12). For example, children born during the Dutch hunger winter of WWII are known to have a greater incidence of obesity than others of similar genetic background born just before or after the war and raised in the same environment (15).

One of the major drawbacks to most weight loss strategies is that they fail to consider how bodies defend themselves from losing energy during periods of starvation. An effective weight loss strategy should not only focus on weight loss, but also on the maintenance of a stable bodyweight afterwards. Traditional diet and exercise, despite being effective at reducing bodyweight acutely, often have a refractory period that favors weight gain, restoring body mass to the pre-intervention levels in both rodent and human models (16-18). This suggests that bodies have a preprogrammed weight they try to maintain by adjusting appetite and energy expenditure within the new metabolic milieu. It is also worth noting that experimental subjects resisted weight gain to a certain extent when they were force fed, suggesting that humans are equipped to maintain body mass within a relatively narrow range (19). Although our bodies aim to preserve a stable body mass, there does appear to be a slight bias towards weight gain (20).

\section{THE BRAIN AS AN OBESITY TARGET TISSUE}

The brain has long been recognized as a key tissue in the development of obesity and diabetes, a target that is sometimes overlooked in contemporary research. The French physiologist Claude Bernard established in 1849 that the brain plays a critical role in the regulation of blood glucose (21). By damaging the brain's fourth ventricle, by way of a "piqure diabetique", he was able to induce diabetes in dogs and others have successfully repeated these experiments in different animal models (22). Studies in the early part of this century revealed that other brain regions, including the hypothalamus, are also critical centers involved in the modulation of peripheral glucose homeostasis (23). Further, when a significant proportion of hypothalamic neurons are damaged, excessive weight gain and the development of diabetes ensued $(24,25)$. It is now widely accepted that there are two key populations of hypothalamic neurons involved in bodyweight regulation; a) the anorexigenic melanocortin neurons which express proopiomelancortin (POMC) and reduce appetite while elevating energy expenditure and b) the orexigenic neurons that express neuropeptide Y (NPY) which have the opposite effects on central energy metabolism (26). Even slight imbalances between the outputs from these neurons can lead to an inappropriate increase in appetite and reduction in energy expenditure which can results in a progressive and significant weight gain over several years (27).

The efficiency and accuracy with which bodyweight is regulated is incredible given the daily variations in activity and food consumption $(2,19)$. Hervey (1969) points out that between the ages of 25 and 65 a women will gain on average only $11 \mathrm{Kg}$; however what is remarkable is that she will consume over 20 tons of food during that period (28). This suggests that our bodies are approximately $99.7 \%$ efficient at controlling 


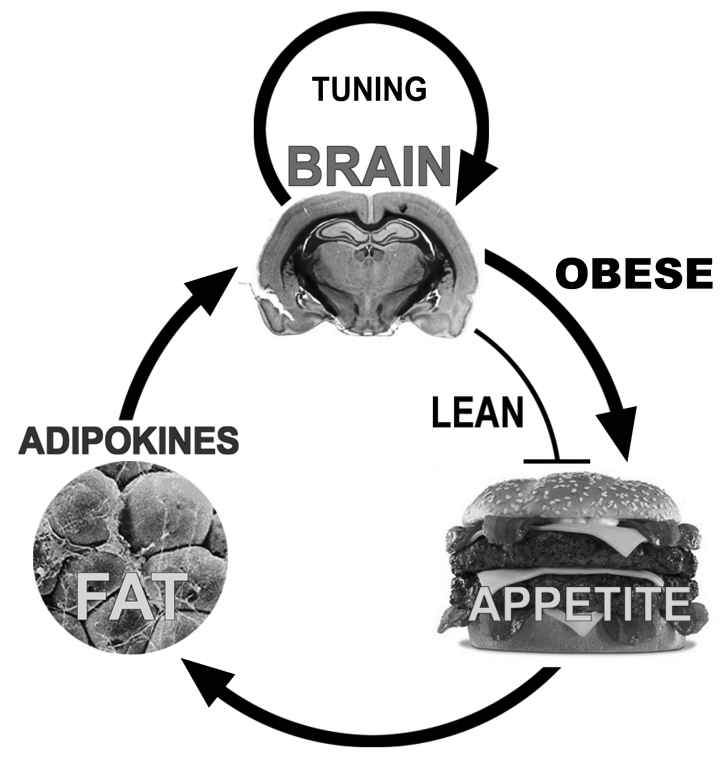

Figure 1: Brain adipokines and a modified lipostatic loop It has been more than 50 years since Kennedy first proposed the existence of a lipostatic loop in which body fat controls energy metabolism via a hypothalamic-dependent mechanism. It is believed that when adipose tissue mass is increased by consuming an excess of food, leptin is then released into circulation in a proportionate manner so it gain access to the hypothalamus in order to reduce appetite and to promote energy expenditure. However obesity is characterized by a resistance to these peripheral adiposity signals, so normal satiety mechanisms fail to shut off appetite, which leads to further food consumption and a continuous cycle of weight gain. Since brainderived adipokines appeared to modify key cell signaling (i.e. socs-3) and energy sensing (i.e. AMPK) pathways implicated in central energy metabolism, we hypothesize that centrally expressed adipokines might form a local hypothalamic 'tuning' mechanism which provides the finesse required to precisely match food intake and energy expenditure, which is approximately $99.7 \%$ efficient. Thus modifying the expression of hypothalamic-derived adipokines might provide us with a means to increase the brain's sensitivity to peripheral metabolic signals and help restore some of the metabolic mismatch that characterizes obesity.

our weight, as previously calculated by others (29). Although it is now widely accepted that bodyweight regulation involves a coordinated response with the aforementioned hypothalamic neuronal populations (i.e balance between NPY and POMC neuronal output), many hypotheses have been put forth over the years as to which metabolic signals are regulating the activity of these neurons. These hypotheses include: a body temperature-dependent indication of energy stores, a glucostatic system, and the now widely accepted lipostatic theory (30). In the latter model it was thought that increase or decrease in body fat generated changes in unknown adiposity signal(s) that could then modify the activity of the hypothalamic pathways involved in the control of appetite and energy expenditure (Figure 1). This model was validated following the cloning of the anorexigenic hormone leptin from adipose tissue, (31). It is also worth noting that several other peripheral metabolic signals including insulin, ghrelin, polypeptide Y3-36 (PYY3-36), cholecystokinin (CCK), which are produced in a variety of tissues, are also modulating the activity of the aforementioned hypothalamic feeding centers $(26,32,33)$.

\section{THE EMERGING ENDOCRINE ROLE OF ADIPOSE TISSUE}

The cloning of the ob gene by J.M. Friedman's laboratory, which codes for leptin, is arguably one of the most critical steps that initiated the ongoing study of energy balance and bodyweight regulation (31). When leptin is provided to leptin-deficient mice (ob/ob), or humans, it is capable of inducing a pronounced and sustained weight loss $(34,35)$. Subsequent investigations by several research groups revealed that leptin is but one of a large family of factors secreted by adipocytes (adipokines: (36)). These include resistin (37); adiponectin (38), FIAF (fasting-induced adipose factor)(39); visfatin (40); vaspin (41), and a few unexpected candidates including nerve growth factor (42). Application of mass spectrometry-based proteomic techniques will likely enlarge this list of adipocyte secreted proteins $(43,44)$. Many of these targets have been implicated in the regulation of appetite, energy expenditure, insulin sensitivity, and glycemic control, in addition to several other functions $(45,46)$. Thus adipokines represent a group of obesity-related drug targets that could potentially be harnessed to control bodyweight or treat obesity-related illnesses such as cardiovascular disease and diabetes, but might also impact local adipocyte metabolism via autocrine or paracrine mechanisms.

\section{LEPTIN: COMPLETING THE FAT-BRAIN 'LIPOSTATIC' LOOP?}

It has been more than fifty years since Kennedy first hypothesized that the brain senses fat stores in order to control food intake, thus forming an 'lipostatic' system which functions to maintain a relatively stable bodyweight (Figure 1) (30). As described above, this model postulated that an unknown adiposity signal was secreted in proportion to body fat stores which acted on the brain in order to regulate appetite and energy expenditure in order to maintain a stable energy balance. It took more than 4 decades in order for an adiposity factor(s) to be identified which could be responsible for influencing the central metabolic pathways. The cloning of the ob gene (leptin) revived the 'lipostatic' hypothesis since its expression directly correlates with the amount of adipose tissue present, i.e. large adipose stores are associated with increased levels of leptin mRNA in ob/ob mice (31) and the degree of adiposity is positively correlated with plasma leptin concentrations (47). Given that the expression and 
release of leptin occurs in response to changes in metabolic status (i.e. high or low energy stores augment or reduce leptin levels respectively) (48), and that leptin influences central metabolic pathways (49), it was believed that leptin was the missing energy gauge that acted on the hypothalamus in order to regulate energy metabolism.

Defects in the lipostatic system are likely to contribute to great weight gain. However, it is exceedingly rare to find obese individuals who are totally devoid of leptin. Only a handful of leptin deficient individuals have been identified in the world $(34,50)$, yet obesity rates are soaring. In fact, excess bodyweight has been positively correlated with higher circulating leptin levels in the majority of individuals (51). This suggests that the problem resides with how the brain is receiving and interpreting peripheral metabolic signals, which results in an energy imbalance and the inappropriate stimulation of appetite. In other words the brain in an obese patient fails to appropriately reduce appetite and food seeking behaviors, and does not feel satiety despite having an adequate nutrition (52). Obesity appears to be characterized by a state of resistance to anorexigenic signals, such as leptin. The hypothalamic insensitivity to peripheral adiposity signals has been attributed, in part, to modest increases in the level of signaling molecules such as suppressor of cytokine signaling-3 (SOCS-3) $(53,54)$. SOCS-3 binds to the intracellular domains of leptin and insulin receptors thereby creating a molecular traffic jam which prevents these anorexigenic hormones from stimulating the signaling events which lead to reductions in appetite. Therefore very modest, but chronic, increases in hypothalamic SOCS-3 can lead to an inappropriate increase in hunger and hyperglycemia since the brain is unable to interpret the messages meant to indicate that the body is adequately nourished. Other molecular disrupters of hypothalamic adiposity signaling events have also been identified, including protein tyrosine phosphatase 1B. It has also been proposed that leptin resistance occurs at other sites, such as at the level of the blood brain barrier (BBB). In other words, leptin fails to cross the BBB, therefore is unable to gain access to the hypothalamus, failing to induce any weight lowering effect (55). Obesity appears to be characterized by a central desensitization to peripheral adiposity signals, which are often produced in excess.

\section{COULD BRAIN-DERIVED ADIPOKINES BE IMPACTING THE LIPOSTATIC LOOP?}

Subsequent studies have shown that leptin is expressed in a variety of tissues, most notably the central nervous system (56). In addition to leptin (57), the brain, pituitary gland and several brain cell line models expresses a variety of adipokines including adiponutrin (58), resistin $(59,60)$ and FIAF (61). This led to the hypothesis that brain-derived adipokines might be serving an autocrine or paracrine role in which they influence the regulation of appetite and impact normal brain function (56). However a major criticism has been that adipokine gene expression in non-adipose tissues, in particular the brain and pituitary, is too low to serve any biological effect $(62,63)$. However, low mRNA abundance does not preclude a functional role for brain-derived adipokines (56). A notable example includes the low level of leptin receptor mRNA detected in some brain areas, even though receptor protein levels are readily detected using immunocytochemistry $(64,65)$. Likewise, despite the low levels of leptin mRNA present in the human hypothalamus, it was shown that there is a net release of leptin from the human brain $(66,67)$. One approach to investigate the role of brain-derived adipokines is to specifically silence their expression and to evaluate the consequences on cell survival, signaling or metabolic pathways. Although advances in molecular biology have provided a variety of techniques that permit the specific manipulation of target gene expression, RNA interference (RNAi) is by far one of the most eminent. This technique has been instrumental in the establishment of gene function in a number of in vitro and in vivo models, most notably in the central nervous system (68-70).

Leptin has been implicated in a variety of brain functions in addition to its role in the control and regulation of appetite. One of the less prominent features of the leptin deficient ob/ob mouse is its reduced brain size and decreased cell number, which could be corrected by leptin treatment (71). Subsequent studies revealed that leptin also possesses trophic properties that impact the hard wiring of the hypothalamus during a critical neonatal period (72). Hypothalamic neuronal plasticity is also affected since leptin administration rapidly modified critical synaptic connections implicated in the control of appetite (73). Leptin gene expression was found to be developmentally regulated in the rat brain and pituitary gland (74). Leptin gene expression could also be induced in the rat brain following traumatic brain injury (TBI) (75). Subsequently, when RNAi was used to specifically silence leptin gene expression in rat C6 glioblastoma cell line, a model previously validated (76), the result was a significant 2 -fold increase in cell death as detected using either TUNEL $(\mathrm{P}<0.005)$ or ethidium homodimer-1 $(\mathrm{P}<0.015)$ staining $(77)$. This was also consistent with anti-apoptotic pathways that were induced by leptin treatment in the human SHSY5Y neuroblastoma cell line (78). Together these 
results suggest that centrally-derived leptin might be involved in normal brain function in addition to impacting the development of the central nervous system (CNS), neuronal plasticity and wiring, or even brain repair following injury.

To further investigate the novel interaction between brain adipokines, RNAi studies on resistin and fiaf, adipokines implicated in glucose and lipid metabolism $(37,39)$, were carried out in the novel N-1 hypothalamic neuronal cell line (79). These cells were chosen since they were derived from the embryonic mouse hypothalamus and express a range of neuropeptides involved in normal hypothalamic function and metabolism. Although fiaf expression was significantly reduced using a chemically modified small interfering RNA (siRNA), this failed to significantly modify the expression of other genes being analysed (60). In marked contrast, the RNAi-mediated silencing of rstn induced significant increases $(>50 \%)$ in both fiaf and suppressor of cytokine signaling-3 (socs-3) when N-1 cells were cultured in serum-deprived medium (60). Likewise, resistin knockdown also reduced the ratio of phosphorylated total adenosine monophosphateactivated protein kinase (AMPK) (80), a novel energy sensor implicated in the hypothalamic control of appetite and hepatic gluconeogenesis (81-83). Additionally the effects on fiaf and socs-3 expression, or changes in AMPK activation, were reversed when N1 cells were treated with resistin, or transfected with a resistin-expressing plasmid (60). Thus brain-derived adipokines appear capable of regulating metabolic signaling events (e.g. socs-3) and cellular energy metabolism (e.g. AMPK) which might have significant consequences on the central regulation of appetite and energy expenditure.

Preliminary in vivo studies also confirmed that RNAi was an effective means to acutely block the nutritionally-mediated induction of brain-derived leptin in the adult male rat. The intracerebroventricular (icv) injection of a leptin-specific siRNA molecule into the dorsal 3rd ventricle (D3V) of fasted rats, as done by others for brain-derived neurotrophic factor (BDNF) (84), attenuated the feeding-induced increase in hypothalamic leptin mRNA by more than $75 \%$ $(\mathrm{p}<0.01)$. This acute knockdown $(24 \mathrm{~h})$ resulted in a slightly greater overnight weight gain $(+15 \%, \mathrm{p}<0.05)$, relative to rats that received the non-specific control molecule. Similarly the continuous infusion of the 'naked' leptin-specific siRNA into the LV resulted in a modest, but non-significant, reduction of leptin mRNA $(-30 \%)$ in the cortex and hypothalamus. Although no increases in body weight were detected in the rats that were continuously infused with the leptin-specific siRNA, this could be due to the poor leptin knockdown achieved. However leptin knockdown reduced the expression of cortical resistin $(-35 \%, \mathrm{p}<0.05)$, but paradoxically increased hypothalamic resistin by 2 -fold $(\mathrm{p}<0.05)$, as measured by realtime RT-PCR. Thus brainderived leptin appears to regulate the expression of other centrally derived adipokines, although these effects appear dependent on the cell-type or brain region being analyzed. An important technical goal remains to improve the magnitude and length of silencing achieved under basal conditions in vivo as this greater reduction in brain leptin expression might induce a more pronounced phenotype.

\section{BRAIN ADIPOKINES AND AN ENDOGENOUS METABOLIC TUNING MECHANISM}

These preliminary studies suggest that brain-derived adipokines are capable of influencing brain cell survival (e.g. leptin and C6), signaling (e.g. N-1 and socs-3), or metabolic sensing (e.g. N-1 and AMPK). In addition there appears to be a complex interrelationship between centrally-derived adipokines both in vitro and in vivo. Further studies are now needed to investigate the effects of silencing brain-derived adipokines during critical developmental periods, which might impact normal brain development and function. Although adipose tissue appears to provide the hypothalamus with the bulk of the peripheral metabolic signals that act as gross indicators of energy availability $(26,32,85,86)$, it is uncertain whether these signals alone can provide the hypothalamus with the finesse that is required to delicately and efficiently control bodyweight $(2,28)$. Perhaps the crosstalk that appears to be occurring between centrally-derived adipokines in vivo (e.g. leptin and resistin) could form a fine-tuning mechanism that contributes to the precise and accurate regulation of hypothalamic metabolic pathways via autocrine or paracrine mechanisms (Figure 1). Thus in the context of the lipostatic loop model, minor disruptions in hypothalamic adipokine gene expression appear capable of impacting the efficiency of this tightly regulated system. Slight perturbations in this hypothetical central adipokine system might lead to a metabolic mismatch that increases the risk of gaining weight or developing insulin resistance by impacting the hypothalamic sensitivity and receptivity to peripheral adiposity signals. As such, adjusting this central system might allow us to improve the efficiency of this lipostatic loop, and might even prove to be a means to promote weight loss and help change the bodyweight set point in obese individuals.

\section{CONCLUSION}

Obesity is a complex and often poorly understood medical condition that results in unnecessary 
psychological and physical suffering. Despite the negative stereotypes associated with the obese, it is important to recognize that deeper physiological and genetic mechanisms might also contribute to excessive adiposity (10-12). It is worth considering how even the most minor of imbalances between food intake and energy expenditure can lead to a significant and unintended weight gain over only a few years $(2,28)$, and this metabolic mismatch has only been further exacerbated in recent years by the over abundance of highly palatable foods that are readily available on a daily basis (14). Although we do not refute that diet and exercise can promote weight loss, we can not ignore the poor outcome of these programs in the long term $(9,16$ 18). Therefore, it is necessary to investigate other avenues, such as the role of brain-derived adipokine in normal body weight regulation and energy metabolism which might prove useful to promote weight loss. However given the complexity and redundancy of the endogenous mechanisms that are in place to maintain bodyweight, it seems likely that multiple approaches will be required to effectively treat obesity.

\section{ACKNOWLEDGMENTS}

The studies in our laboratory were made possible by financial support from the NSHRF, the IWK Health Centre, the Atlee Endowment, UIMRF and Capital Health. RB was the recipient of a NSHRF Graduate Studentship. I am indebted to Dr D.D. Belsham (University of Toronto) for the generous gift of N-1 hypothalamic neurons, and to Drs. Imran, Ur and Wilkinson for their support. D.Wilkinson and P.Wilkinson provided invaluable support and technical assistance.

\section{REFERENCES}

1 Keith SW, Redden DT, et al. Putative contributors to the secular increase in obesity: Exploring the roads less traveled. Int J Obes 2006;30:1585-1594.

2 Bray GA. Good calories, bad calories by gary taubes; new york: Aa knopf. Obes Rev 2008

3 Katzmarzyk PT. The Canadian obesity epidemic, 1985-1998. CMAJ. 2002;166:1039-1040.

4 Prentice AM. The emerging epidemic of obesity in developing countries. Int J Epidemiol 2006;35:93-99.

5 Trifiletti LB, Shields W, Bishai D, McDonald E, Reynaud F, Gielen A. Tipping the scales: Obese children and child safety seats. Pediatrics 2006;117:1197-1202.

6 Olshansky SJ, Passaro DJ,et al. A potential decline in life expectancy in the united states in the 21 st century. $\mathrm{N}$ Engl $\mathrm{J}$ Med 2005;352:1138-1145.

7 Pinhas-Hamiel O, Zeitler P. The global spread of type 2 diabetes mellitus in children and adolescents. J Pediatr 2005;146:693700 .

8 Katzmarzyk PT, Janssen I. The economic costs associated with physical inactivity and obesity in canada. An update. Can J Appl
Physiol 2004;29:90-115.

9 Jeffery RW, Drewnowski A, Epstein LH, Stunkard AJ, Wilson GT, Wing RR, Hill DR. Long-term maintenance of weight loss: Current status. Health Psychol 2000;19:5-16.

10 Friedman JM, Leibel RL. Tackling a weighty problem. Cell 1992;69:217-220

11 Blundell JE. Appetite disturbance and the problems of overweight. Drugs 1990;39 Suppl 3:1-19.

12 Stoger R. The thrifty epigenotype: An acquired and heritable predisposition for obesity and diabetes? Bioessays 2008;30:156166.

13 Neel JV. Diabetes mellitus: A "Thrifty" Genotype rendered detrimental by "Progress"? Am J Hum Genet 1962;14:353-362.

14 Hill JO, Wyatt HR, Reed GW, Peters JC. Obesity and the environment: Where do we go from here? Science 2003;299:853-855.

15 Ravelli GP, Stein ZA, Susser MW. Obesity in young men after famine exposure in utero and early infancy. N Engl J Med 1976;295:349-353.

16 Kramer FM, Jeffery RW, Forster JL, Snell MK. Long-term follow-up of behavioral treatment for obesity: Patterns of weight regain among men and women. Int J Obes 1989;13:123-136.

17 Levin BE, Dunn-Meynell AA. Defense of body weight against chronic caloric restriction in obesity-prone and -resistant rats. Am J Physiol Regul Integr Comp Physiol 2000;278:R231-237.

18 Levin BE, Keesey RE. Defense of differing body weight set points in diet-induced obese and resistant rats. Am J Physiol 1998;274:R412-419.

19 Sims EA, Horton ES. Endocrine and metabolic adaptation to obesity and starvation. Am J Clin Nutr 1968;21:1455-1470.

20 Schwartz MW, Woods SC, Seeley RJ, Barsh GS, Baskin DG, Leibel RL. Is the energy homeostasis system inherently biased toward weight gain? Diabetes 2003;52:232-238.

21 Bernard C. Leçons de physiologie experimentale appliqués á là medecine. Paris, Baillere et Fils, 1854.

22 Feldberg W, Pyke D, Stubbs WA. Hyperglycaemia: Imitating claude bernard's piqure with drugs. J Auton Nerv Syst 1985;14:213-228.

23 Donhoffer C, MacLeod JJR. Studies in the nervous control of carbohydrate metabolism. I.--the position of the centre. Proc R Soc Lond B Biol Sci 1932;110:125-141.

24 Pizzi WJ, Barnhart JE. Effects of monosodium glutamate on somatic development, obesity and activity in the mouse. Pharmacol Biochem Behav 1976;5:551-557.

25 Cameron DP, Poon TK, Smith GC. Effects of monosodium glutamate administration in the neonatal period on the diabetic syndrome in kk mice. Diabetologia 1976;12:621-626.

26 Schwartz MW, Porte D, Jr.. Diabetes, obesity, and the brain. Science 2005;307:375-379.

27 Lee M, Korner J. Review of physiology, clinical manifestations, and management of hypothalamic obesity in humans. Pituitary 2008

28 Hervey GR. Regulation of energy balance. Nature 1969;222:629-631.

29 Harris RB. Role of set-point theory in regulation of body weight. Faseb J 1990;4:3310-3318.

30 Kennedy GC. The role of depot fat in the hypothalamic control of food intake in the rat. Proc R Soc Lond B Biol Sci 1953;140:578-596.

31 Zhang Y, Proenca R, Maffei M, Barone M, Leopold L, Friedman JM. Positional cloning of the mouse obese gene and its human homologue. Nature 1994;372:425-432.

32 Badman MK, Flier JS. The gut and energy balance: Visceral allies in the obesity wars. Science 2005;307:1909-1914.

33 Fry M, Hoyda TD, Ferguson AV. Making sense of it: Roles of the sensory circumventricular organs in feeding and regulation 
of energy homeostasis. Exp Biol Med (Maywood) 2007;232:1426.

34 Montague CT, Farooqi IS, et al. Congenital leptin deficiency is associated with severe early-onset obesity in humans. Nature 1997;387:903-908.

35 Halaas JL, Gajiwala KS, Maffei M, Cohen SL, Chait BT, Rabinowitz D, Lallone RL, Burley SK, Friedman JM. Weightreducing effects of the plasma protein encoded by the obese gene. Science 1995;269:543-546.

36 Trayhurn P, Bing C, Wood IS. Adipose tissue and adipokines-energy regulation from the human perspective. J Nutr 2006;136:1935S-1939S

37 Steppan CM, Bailey ST, Bhat S, Brown EJ, Banerjee RR, Wright CM, Patel HR, Ahima RS, Lazar MA. The hormone resistin links obesity to diabetes. Nature 2001;409:307-312.

38 Scherer PE, Williams S, Fogliano M, Baldini G, Lodish HF. A novel serum protein similar to c1q, produced exclusively in adipocytes. J Biol Chem 1995;270:26746-26749.

39 Kersten S, Mandard S, Tan NS, Escher P, Metzger D, Chambon P, Gonzalez FJ, Desvergne B, Wahli W. Characterization of the fasting-induced adipose factor fiaf, a novel peroxisome proliferator-activated receptor target gene. J Biol Chem 2000;275:28488-28493

40 Fukuhara A, Matsuda M, et al. Visfatin. A protein secreted by visceral fat that mimics the effects of insulin. Science 2005;307:426-430.

41 Hida K, Wada J, Eguchi J, Zhang H, Baba M, Seida A, Hashimoto I, Okada T, Yasuhara A, Nakatsuka A, Shikata K, Hourai S, Futami J, Watanabe E, Matsuki Y, Hiramatsu R, Akagi S, Makino H, Kanwar YS. Visceral adipose tissue-derived serine protease inhibitor: A unique insulin-sensitizing adipocytokine in obesity. Proc Natl Acad Sci U S A 2005;102.10610-10615.

42 Bullo M, Peeraully MR, Trayhurn P: Stimulation of ngf expression and secretion in 3t3-11 adipocytes by prostaglandins pgd2, pgj2, and delta12-pgj2. Am J Physiol Endocrinol Metab 2005;289.E62-67.

43 Kratchmarova I, Kalume DE, Blagoev B, Scherer PE, Podtelejnikov AV, Molina H, Bickel PE, Andersen JS, Fernandez MM, Bunkenborg J, Roepstorff P, Kristiansen K, Lodish HF, Mann M, Pandey A. A proteomic approach for identification of secreted proteins during the differentiation of 3t3-11 preadipocytes to adipocytes. Mol Cell Proteomics 2002;1:213-222.

44 Yang YS, Song HD, Li RY, Zhou LB, Zhu ZD, Hu RM, Han ZG, Chen JL. The gene expression profiling of human visceral adipose tissue and its secretory functions. Biochem Biophys Res Commun 2003;300:839-846.

45 Ahima RS. Adipose tissue as an endocrine organ. Obesity (Silver Spring) 2006;14 Suppl 5:242S-249S

46 Ahima RS, Lazar MA. Adipokines and the peripheral and neural control of energy balance. Mol Endocrinol 2008;22:1023-1031.

47 Schwartz MW, Peskind E, Raskind M, Boyko EJ, Porte D, Jr.. Cerebrospinal fluid leptin levels: Relationship to plasma levels and to adiposity in humans. Nat Med 1996;2:589-593.

48 Becker DJ, Ongemba LN, Brichard V, Henquin JC, Brichard SM. Diet- and diabetes-induced changes of ob gene expression in rat adipose tissue. FEBS Lett 1995;371:324-328.

49 Campfield LA, Smith FJ, Guisez Y, Devos R, Burn P. Recombinant mouse ob protein: Evidence for a peripheral signal linking adiposity and central neural networks. Science 1995;269:546-549.

50 Licinio J, Caglayan S, Ozata M, Yildiz BO, de Miranda PB, O'Kirwan F, Whitby R, Liang L, Cohen P, Bhasin S, Krauss RM, Veldhuis JD, Wagner AJ, DePaoli AM, McCann SM, Wong ML. Phenotypic effects of leptin replacement on morbid obesity, diabetes mellitus, hypogonadism, and behavior in leptin- deficient adults. Proc Natl Acad Sci U S A 2004;101:4531-4536.

51 Frederich RC, Hamann A, Anderson S, Lollmann B, Lowell BB, Flier JS. Leptin levels reflect body lipid content in mice: Evidence for diet-induced resistance to leptin action. Nat Med 1995;1:1311-1314.

52 Jackson MB, Ahima RS. Neuroendocrine and metabolic effects of adipocyte-derived hormones. Clin Sci (Lond) 2006;110:143152.

53 Bjorbaek C, El-Haschimi K, Frantz JD, Flier JS. The role of socs-3 in leptin signaling and leptin resistance. J Biol Chem 1999;274:30059-30065.

54 Munzberg H, Myers MG, Jr.. Molecular and anatomical determinants of central leptin resistance. Nat Neurosci 2005;8:566-570.

55 Banks WA, Farrell CL. Impaired transport of leptin across the blood-brain barrier in obesity is acquired and reversible. Am J Physiol Endocrinol Metab 2003;285:E10-15.

56 Wilkinson M, Brown R, Imran SA, Ur E: Adipokine gene expression in brain and pituitary gland. Neuroendocrinology 2007;86:191-209.

57 Morash B, Li A, Murphy PR, Wilkinson M, Ur E. Leptin gene expression in the brain and pituitary gland. Endocrinology 1999; 140:5995-5998

58 Wiesner G, Morash BA, Ur E, Wilkinson M. Food restriction regulates adipose-specific cytokines in pituitary gland but not in hypothalamus. J Endocrinol 2004;180:R1-6.

59 Morash BA, Wilkinson D, Ur E, Wilkinson M. Resistin expression and regulation in mouse pituitary. FEBS Lett 2002;526:26-30.

60 Brown R, Imran SA, Belsham DD, Ur E, Wilkinson M. Adipokine gene expression in a novel hypothalamic neuronal cell line: Resistin-dependent regulation of fasting-induced adipose factor and socs-3. Neuroendocrinology 2007;85:232241.

61 Wiesner G, Brown RE, Robertson GS, Imran SA, Ur E, Wilkinson M. Increased expression of the adipokine genes resistin and fasting-induced adipose factor in hypoxic/ischaemic mouse brain. Neuroreport 2006;17:1195-1198.

62 Steppan CM, Lazar MA: The current biology of resistin. J Intern Med 2004;255:439-447.

63 Sahu A. Leptin signaling in the hypothalamus: Emphasis on energy homeostasis and leptin resistance. Front Neuroendocrinol 2003;24:225-253.

64 Elmquist JK, Bjorbaek C, Ahima RS, Flier JS, Saper CB. Distributions of leptin receptor mrna isoforms in the rat brain. J Comp Neurol 1998;395:535-547.

65 Hakansson ML, Brown H, Ghilardi N, Skoda RC, Meister B. Leptin receptor immunoreactivity in chemically defined target neurons of the hypothalamus. J Neurosci 1998;18:559-572.

66 Wiesner G, Vaz M, Collier G, Seals D, Kaye D, Jennings G, Lambert G, Wilkinson D, Esler M. Leptin is released from the human brain: Influence of adiposity and gender. J Clin Endocrinol Metab 1999;84:2270-2274.

67 Eikelis N, Esler M, Barton D, Dawood T, Wiesner G, Lambert G. Reduced brain leptin in patients with major depressive disorder and in suicide victims. Mol Psychiatry 2006;11:800-801.

68 Thakker DR, Hoyer D, Cryan JF. Interfering with the brain: Use of rna interference for understanding the pathophysiology of psychiatric and neurological disorders. Pharmacol Ther 2006;109:413-438.

69 Gan L, Anton KE, Masterson BA, Vincent VA, Ye S, GonzalezZulueta M. Specific interference with gene expression and gene function mediated by long dsrna in neural cells. J Neurosci Methods 2002;121:151-157.

70 Fire A, Xu S, Montgomery MK, Kostas SA, Driver SE, Mello CC. Potent and specific genetic interference by double-stranded 
rna in caenorhabditis elegans. Nature 1998;391:806-811.

71 Steppan CM, Swick AG. A role for leptin in brain development. Biochem Biophys Res Commun 1999;256:600-602.

72 Bouret SG, Draper SJ, Simerly RB. Trophic action of leptin on hypothalamic neurons that regulate feeding. Science 2004;304:108-110.

73 Pinto S, Roseberry AG, Liu H, Diano S, Shanabrough M, Cai X, Friedman JM, Horvath TL. Rapid rewiring of arcuate nucleus feeding circuits by leptin. Science 2004;304:110-115.

74 Morash B, Wilkinson D, Murphy P, Ur E, Wilkinson M. Developmental regulation of leptin gene expression in rat brain and pituitary. Mol Cell Endocrinol 2001;185:151-159.

75 Brown R, Thompson HJ, Imran SA, Ur E, Wilkinson M. Traumatic brain injury induces adipokine gene expression in rat brain. Neurosci Lett 2008;432:73-78.

76 Morash B, Johnstone J, Leopold C, Li A, Murphy P, Ur E, Wilkinson M. The regulation of leptin gene expression in the $\mathrm{c} 6$ glioblastoma cell line. Mol Cell Endocrinol 2000;165:97-105.

77 Brown R, Morash B, Ur E, Wilkinson M. Rnai-mediated silencing of leptin gene expression increases cell death in c6 glioblastoma cells. Brain Res Mol Brain Res 2005;139:357-360.

78 Russo VC, Metaxas S, Kobayashi K, Harris M, Werther GA. Antiapoptotic effects of leptin in human neuroblastoma cells. Endocrinology 2004;145:4103-4112.

79 Belsham DD, Cai F, Cui H, Smukler SR, Salapatek AM, Shkreta L. Generation of a phenotypic array of hypothalamic neuronal cell models to study complex neuroendocrine disorders.
Endocrinology 2004;145:393-400.

80 Brown R, Wilkinson P, Imran SA, Ur E, Wilkinson M. Resistin activates amp-activated protein kinase in a novel hypothalamic neuronal cell line: Implications for central energy metabolism. Endocrine abstracts 2008

81 Minokoshi Y, Alquier T, Furukawa N, Kim YB, Lee A, Xue B, Mu J, Foufelle F, Ferre P, Birnbaum MJ, Stuck BJ, Kahn BB. Amp-kinase regulates food intake by responding to hormonal and nutrient signals in the hypothalamus. Nature 2004;428:569574 .

82 McCrimmon RJ, Fan X, Cheng H, McNay E, Chan O, Shaw M, Ding Y, Zhu W, Sherwin RS. Activation of amp-activated protein kinase within the ventromedial hypothalamus amplifies counterregulatory hormone responses in rats with defective counterregulation. Diabetes 2006;55:1755-1760.

83 Kahn BB, Alquier T, Carling D, Hardie DG. Amp-activated protein kinase: Ancient energy gauge provides clues to modern understanding of metabolism. Cell Metab 2005;1:15-25.

84 Baker-Herman TL, Fuller DD, Bavis RW, Zabka AG, Golder FJ, Doperalski NJ, Johnson RA, Watters JJ, Mitchell GS. Bdnf is necessary and sufficient for spinal respiratory plasticity following intermittent hypoxia. Nat Neurosci 2004;7:48-55.

85 Ahima RS. Central actions of adipocyte hormones. Trends Endocrinol Metab 2005; 16:307-313.

86 Ahima RS, Qi Y, Singhal NS. Adipokines that link obesity and diabetes to the hypothalamus. Prog Brain Res 2006;153:155174.

Russell Brown (M.D.C.M. 2011) has served as a senior editor for the MJM over the past year and will be returning as a Co-Editor-In-Chief in the upcoming year. He received a B.Sc (Hons) in Biochemistry and Molecular Biology (2003) and earned a PhD in physiology and Biophysics (2007) both from Dalhousie University (Halifax NS). He is currently a medical student at McGill and continues to be actively involved with investigations that focus on elucidating the various potential role(s) of brain-derived adipokines. 